\title{
Reliability, Maintainability, and Availability Analysis of a Computerized Numerical Control Machine Tool Using Markov Chains
}

\section{Rajkumar Bhimgonda Patil ${ }^{1,2}$, Mohamed Arezki Mellal ${ }^{2,3}$, Anand K. Bewoor ${ }^{4}$, Sameer Al-Dahidi ${ }^{5}$}

${ }^{1}$ Department of Mechanical Engineering, Annasaheb Dange College of Engineering \& Technology, Ashta, India, rbp_mech@adcet.in

${ }^{2}$ Center for Advanced Life Cycle Engineering (CALCE), University of Maryland, College Park, MD, USA

${ }^{3}$ LMSS, Faculty of Technology, M'Hamed Bougara University, Boumerdes, Algeria, mellal.mohamed@univ-boumerdes.dz

${ }^{4}$ Cummins College of Engineering for Women, Pune, India, anand.bewoor@cumminscollege.in

${ }^{5}$ Department of Mechanical and Maintenance Engineering, School of Applied Technical Sciences, German Jordanian University, Amman, Jordan, sameer.aldahidi@gju.edu.jo

Abstract: Reliability, maintainability, and availability analysis of Computerized Numerical Control Machine Tools (CNCMT) is vital as they are widely used in manufacturing industries for mass production. This paper proposes a generalized framework for TimeBetween-Failure (TBF) and Time-To-Repair (TTR) data analysis, integrated with Markov chains for estimating the system's Steady State Availability (SSA). A case study of a typical CNCMT illustrates the applicability and the effectiveness of the proposed framework. The effect of variation of sub-systems' failure and repair rates on the availability of the CNCMT is studied. The critical sub-systems from reliability, maintainability, and availability point of view are identified. The analysis reveals that the CNCMT's failure and repair rates are nearly constant and the CNCMT fails four times per year. The Lubrication Sub-system (LS) is the utmost severe sub-system as far as maintainability aspect is concerned and Turret Sub-system (TS) is the utmost severe sub-system from a reliability perspective.

Keywords: steady-state availability; reliability; maintainability; computerized numerical control machine tool; Markov chains 


\section{Introduction}

Computerized Numerical Control Machine Tools (CNCMT) are the sinews of the modern manufacturing industry and are used for manufacturing various components with high precisions $[1,2,3,4]$. They have become the heart of the machining industry due to their accuracy, flexibility, and productivity. Moreover, machining processes are highly optimized [5,6]. A typical CNCMT consists of many components, and the failure of a single component can hamper the production of an entire workshop or manufacturing system [7, 8]. The cost of maintenance is high when an unexpected failure takes place [9]. Considering these aspects, the manufacturers of the CNCMT should give topmost priority for reliable and maintainable CNCMTs with a desired level of availability.

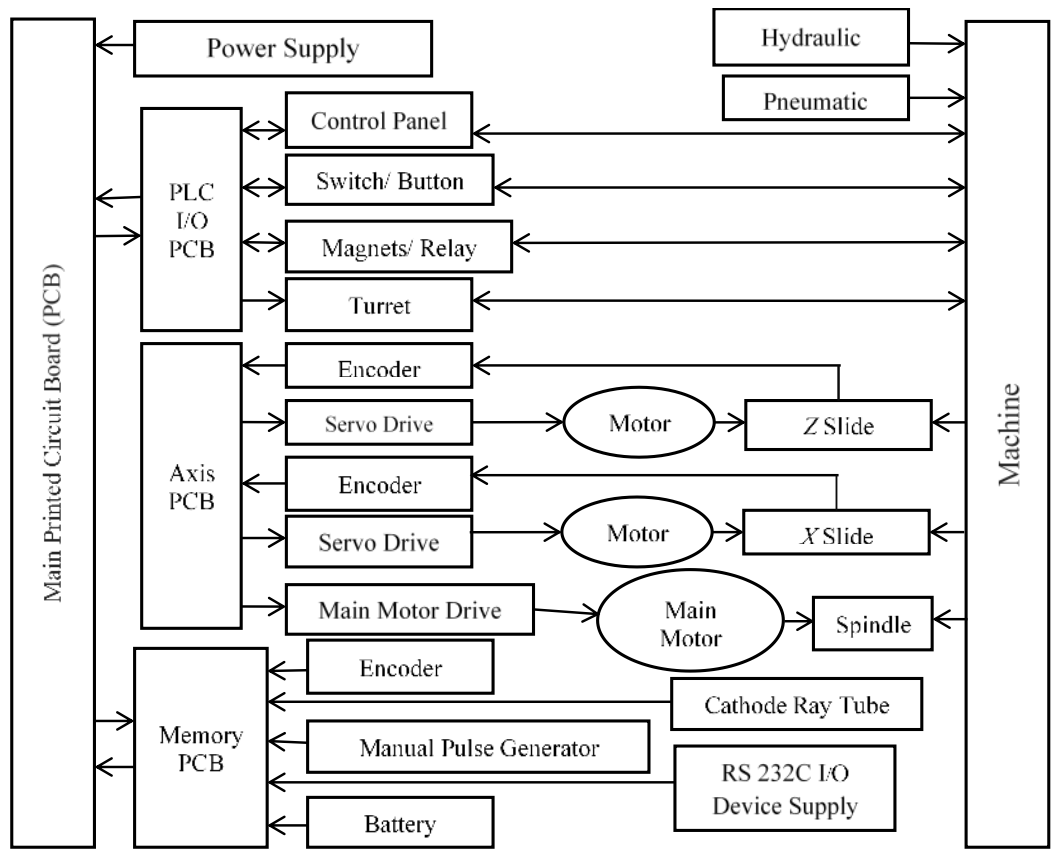

Figure 1

Configuration of a typical CNCMT [2, 9]

The configuration of the typical CNCMT lathes that have $Z$ and $X$ axes driven by AC or DC motors through ball lead screws simultaneously is shown in Figure 1. The turrent may exchange tools automatically. The CNCMT is made up of several sub-systems such as mechanical, hydraulic, pneumatic, electronic, electric, and software. Chuck mounted on the spindle is a mechanical sub-system on which the workpiece to be machined is mounted. The servomotor through the main transmission sub-system rotates the chuck-spindle assembly at the required machining speed. The hydraulic sub-system regulates the clamping and declamping of the workpiece. The cutting tool mounted on the turret moves along 
$X$ - and $Z$ - axes and carry out machining operations. The cutting tool's simultaneous movement along the $X$ - and $Z$-axes is precisely done by the servomotors through lead screws. The turret has an indexing mechanism and is capable of changing the tool automatically as per the machining operations [31]. Cooling, lightening, tail-stock, and pneumatic sub-systems are also incorporated for the ease of machining operations. The motion and operations of different subsystems are controlled with the help of a centralized Computerized Numerical Control (CNC) sub-system that is also called the heart of the CNCMT. The CNC sub-system consists of thousands of electronic components such as Printed Circuit Board (PCB), Programmable Logic Control (PLC), Cathode Ray Tube (CRT) or Medium Dependent Interface (MDI) encoders (for manual date input), limit switches, relays, Manual Pulse Generator (MPG), RS-232 serial communication device, and contactor switches.

Table 1

Sub-systems of CNCMT

\begin{tabular}{|l|c|l|c|}
\hline \multicolumn{1}{|c|}{ Sub-system } & Code & \multicolumn{1}{|c|}{ Sub-system } & Code \\
\hline Main Transmission & MT & Spindle Sub-system & SS \\
\hline Chuck Sub-system & ChS & $X$ and $Z$ Axis Sub-system & XZAS \\
\hline Turret Sub-system & TS & Cooling Sub-system & HS \\
\hline Lubrication Sub-system & LS & Hydraulic Sub-system & EES \\
\hline CNC Sub-system & CNCS & $\begin{array}{l}\text { Electrical and Electronic Sub- } \\
\text { system }\end{array}$ & PS \\
\hline Swarf Conveyor & SC & Pneumatic Sub-system & OS \\
\hline Tail-Stock Sub-system & TSS & Other Sub-system & \\
\hline
\end{tabular}

The CNCMT consists of several sub-systems, assemblies, and components. The sub-systems of the CNCMT are categorized into 14 sub-systems according to their functionality and dependency and reported in Table 1. The failure and repair data collected from the service engineers, maintenance registers and experts in the field are considered for the analysis.

This paper presents a generalized framework for the reliability, maintainability, and availability analysis of the CNCMT. In particular, the Time-Between-Failure (TBF) and Time-To-Repair (TTR) data are analyzed and the proposed framework is integrated with Markov chains to investigate the Steady-State Availability (SSA). The rest of the paper is divided into four sections. Section 2 reviews the main published TBF and TTR data analysis frameworks and reliability analysis of CNCMT over the years. Section 3 presents the proposed new generalized framework developed for the analysis of TBF and TTR data. The selection of sample size for reliability, maintainability, and availability analysis of the CNCMT is presented in Section 4, and the analysis of the results is presented in Section 5. Finally, Section 6 concludes the paper. 


\section{Literature Review}

In 1976, Ferris-Prabhu and Lubart [10] proposed an analytical method for the reliability assessment of a system. The method extended and developed a detailed reliability analysis framework in 1984 conducted by Ascher and Feingold [11]. These modified and extended frameworks were then developed for different applications as per the availability of the data. Abdel-Ghaly et al. [12] presented various statistical tools for predicting software reliability. Kumar et al. [13] investigate Load Hauual Dump (LHD) machines' operational reliability using trend test and goodness-of-fit test. Weibull-Poisson process was developed by Crow [14] and applied to a complex repairable system to predict its reliability. Further, several simplified frameworks were developed and evaluated for the reliability analysis of various systems. Few to mention are: A comprehensive model based on the Bayesian approach was proposed by Pulido et al. [15] and required time-to-failure data. Kim and Yum [16] performed a simulative study to select appropriate distribution between Weibull and lognormal distributions for censored and complete data. Barabady and Kumar [17] applied a reliability data analysis framework to analyze the failure and repair data of a mining plant, present, and predict the reliability and maintainability using best-fit distribution. Louit et al. [18] studied numerous methods used to assess data trends and developed a simplified framework for TBF and TTR data analysis. Several other reliability data analysis and modeling frameworks considering different parameters are also published in the literature [19-24, 36-48]. Table 2 summarizes the review of TBF and TTR data analysis frameworks and models.

Table 2

Review of frameworks and models developed for TBF and TTR data analysis

\begin{tabular}{|c|c|c|c|c|c|c|c|c|c|c|c|c|c|}
\hline Parameters/ techniques & 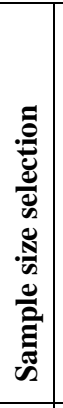 & 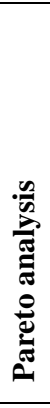 & 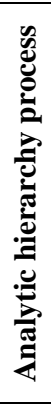 & 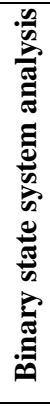 & 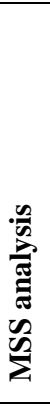 & 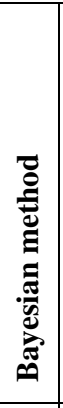 & 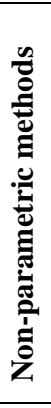 & 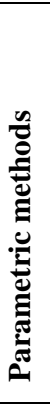 & 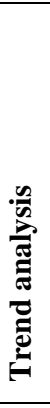 & 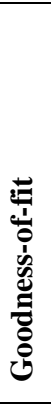 & 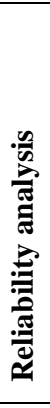 & 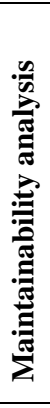 & 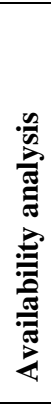 \\
\hline $\begin{array}{ll}\text { Ferris-prabhu } & \text { and } \\
\text { Lubart, 1976, [10] } & \end{array}$ & & & & $\checkmark$ & & & & & & & $\checkmark$ & & \\
\hline $\begin{array}{l}\text { Ascher and Feingold, } \\
\text { 1984, [11] }\end{array}$ & & & & $\checkmark$ & & & & & $\checkmark$ & & $\checkmark$ & & \\
\hline $\begin{array}{l}\text { Abdel-Ghaly et al., } \\
1986,[12]\end{array}$ & & & & & & $\checkmark$ & & & & $\checkmark$ & $\checkmark$ & & \\
\hline Kumar et al., 1989, [13] & & & & & & & & $\checkmark$ & $\checkmark$ & $\checkmark$ & $\checkmark$ & & \\
\hline
\end{tabular}




\begin{tabular}{|c|c|c|c|c|c|c|c|c|c|c|c|c|c|}
\hline Authors & 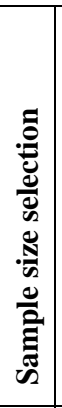 & 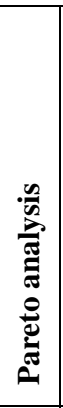 & 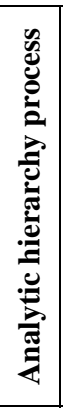 & 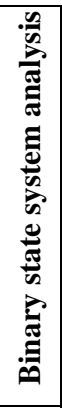 & 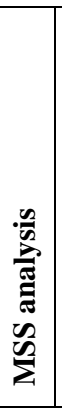 & 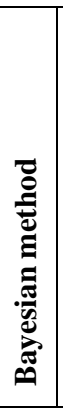 & 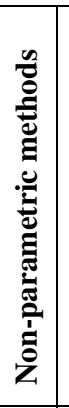 & 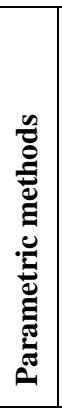 & 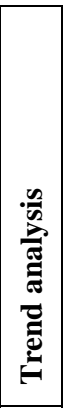 & 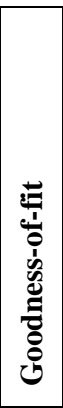 & 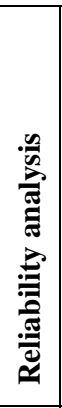 & 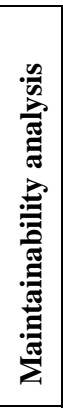 & 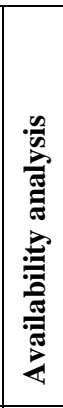 \\
\hline Crow, 1990, [14] & & & & & & & & $\checkmark$ & $\checkmark$ & $\checkmark$ & $\checkmark$ & & \\
\hline $\begin{array}{l}\text { Ansell and Phillips, } \\
\text { 1990, [36] }\end{array}$ & & & & & & & & $\checkmark$ & $\checkmark$ & & $\checkmark$ & & \\
\hline $\begin{array}{l}\text { Kumar and Klefsjo, } \\
\text { 1992, [37] }\end{array}$ & & & & & & & & $\checkmark$ & $\checkmark$ & $\checkmark$ & $\checkmark$ & & \\
\hline $\begin{array}{l}\text { Kumar and Huang, } \\
1993,[38]\end{array}$ & & & & & & & & & & & $\checkmark$ & $\checkmark$ & $\checkmark$ \\
\hline Kamps, 1995 [39] & $\checkmark$ & $\checkmark$ & & & & & & & $\checkmark$ & & & & \\
\hline $\begin{array}{l}\text { Lawless, and } \\
\text { Thiagarajah, 1996, [40] }\end{array}$ & & & & & & & & $\checkmark$ & $\checkmark$ & $\checkmark$ & $\checkmark$ & & \\
\hline Coetzee, 1997, [41] & & & & & & & & $\checkmark$ & $\checkmark$ & $\checkmark$ & $\checkmark$ & $\checkmark$ & \\
\hline $\begin{array}{l}\text { Kvaloy, and Lindqvist, } \\
\text { 1998, [42] }\end{array}$ & & & & & & & & $\checkmark$ & $\checkmark$ & & & & \\
\hline Ziegel, 2001, [43] & & & & & & & & $\checkmark$ & $\checkmark$ & $\checkmark$ & $\checkmark$ & $\checkmark$ & \\
\hline Yanez et al., 2002, [44] & & & & & & & & & $\checkmark$ & & & & \\
\hline $\begin{array}{l}\text { Lindqvist et al., 2003, } \\
\text { [45] }\end{array}$ & & & & & & & & $\checkmark$ & $\checkmark$ & & & & \\
\hline $\begin{array}{l}\text { Samanta et al., 2004, } \\
{[46]}\end{array}$ & & & & & & & & & & & $\checkmark$ & $\checkmark$ & $\checkmark$ \\
\hline Wang, 2005, [47] & & & & & & & & & $\checkmark$ & & & & \\
\hline Lindqvist, 2006, [48] & & & & & & & & & $\checkmark$ & & & & \\
\hline $\begin{array}{l}\text { Kim and Yum, 2008, } \\
{[16]}\end{array}$ & & & & & & & & $\checkmark$ & & & & & \\
\hline $\begin{array}{l}\text { Barabady and Kumar, } \\
2008,[17]\end{array}$ & & $\checkmark$ & & $\checkmark$ & & & & $\checkmark$ & $\checkmark$ & $\checkmark$ & $\checkmark$ & $\checkmark$ & $\checkmark$ \\
\hline Louit et al., 2009, [18] & & & & $\checkmark$ & & $\checkmark$ & & $\checkmark$ & $\checkmark$ & $\checkmark$ & $\checkmark$ & & \\
\hline $\begin{array}{l}\text { Regattieri et al., 2010, } \\
{[19]}\end{array}$ & & & & & & & & $\checkmark$ & & & $\checkmark$ & & \\
\hline $\begin{array}{l}\text { Lad and Kulkarni, 2010, } \\
{[20]}\end{array}$ & & & & & & & & $\checkmark$ & & & $\checkmark$ & & \\
\hline $\begin{array}{l}\text { Castet and Saleh, 2010, } \\
\text { [21] }\end{array}$ & & & & & $\checkmark$ & & $\checkmark$ & $\checkmark$ & & & $\checkmark$ & & \\
\hline Barabadi, 2013, [22] & & & & & & & & $\checkmark$ & & & $\checkmark$ & & \\
\hline $\begin{array}{l}\text { Barabadi et al., 2014, } \\
\text { [23] }\end{array}$ & & & & & & & & $\checkmark$ & & & $\checkmark$ & & \\
\hline
\end{tabular}




\begin{tabular}{|c|c|c|c|c|c|c|c|c|c|c|c|c|c|}
\hline Parameters/ techniques & 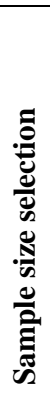 & 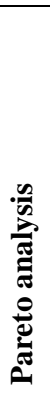 & 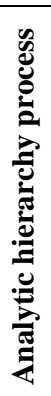 & 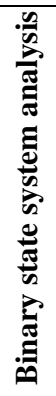 & 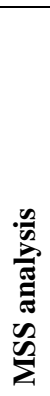 & 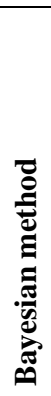 & 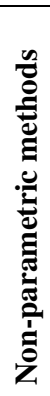 & 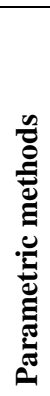 & 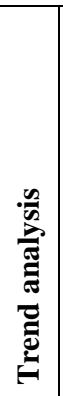 & 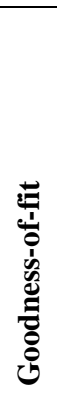 & 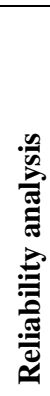 & 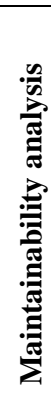 & 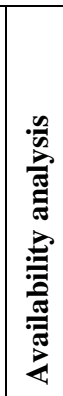 \\
\hline $\begin{array}{l}\text { Bobrowski et al., 2015, } \\
\text { [24] }\end{array}$ & & & & & & & $\checkmark$ & $\checkmark$ & & & $\checkmark$ & & \\
\hline
\end{tabular}

Reliability analysis CNCMTs are being conducted since 1982. The first study on reliability, maintainability, and availability analysis of CNCMTs was presented by Keller et al. [9]. Table 3 summarizes the reliability studies on the CNCMTs, such as the machining center, lathe, and milling center. It can be observed that most of these studies have been conducted based on some particular distributions for data analysis, and few of them used goodness of fit tests. Therefore, there is a need to apply statistical tests to assess the data trends and estimate appropriate distribution to accurately estimate the reliability metric. Statistical tests help to identify anomalies present in the data, trends in the data, and the amount of samples required for the analysis. The field failure data often consists of outliers entered due to human errors and needs to be removed from the sample. Furthermore, over the period of time maintenance policies may be changing that if any needs to tranced to minimize variations in the data. Statistical tests and trend analysis methods are, therefore, useful for refining the field failure data.

Table 3

Review of reliability analysis of CNC assisted machine tools

\begin{tabular}{|c|c|c|c|c|c|c|c|c|c|c|c|c|c|}
\hline $\begin{array}{r}\text { Parameters/ } \\
\text { techniques }\end{array}$ & 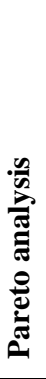 & 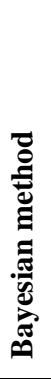 & 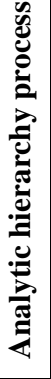 & 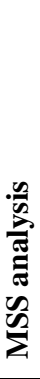 & 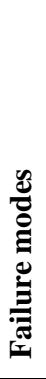 & 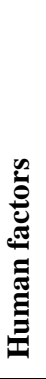 & 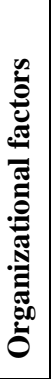 & 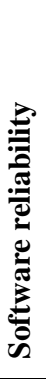 & 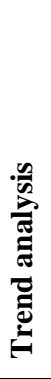 & 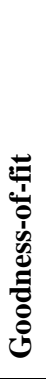 & 莺 & 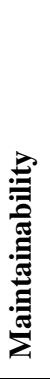 & 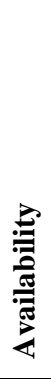 \\
\hline Keller et al., 1982, [9] & $\checkmark$ & $\checkmark$ & & & & & & & & & $\checkmark$ & $\checkmark$ & $\checkmark$ \\
\hline $\begin{array}{l}\text { McGoldrick and } \\
\text { Kulluk, 1986, [49] }\end{array}$ & $\checkmark$ & & & & & & & & & & $\checkmark$ & & \\
\hline $\begin{array}{l}\text { Gupta and Somers, } \\
1989,[50]\end{array}$ & $\checkmark$ & & & & & & & & & & $\checkmark$ & & $\checkmark$ \\
\hline
\end{tabular}




\begin{tabular}{|c|c|c|c|c|c|c|c|c|c|c|c|c|c|}
\hline $\begin{array}{l}\begin{array}{r}\text { Parameters/ } \\
\text { techniques }\end{array} \\
\text { Authors }\end{array}$ & 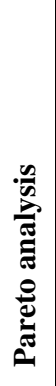 & 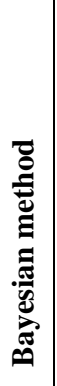 & 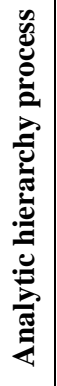 & 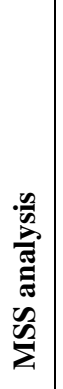 & 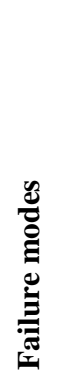 & 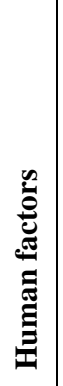 & 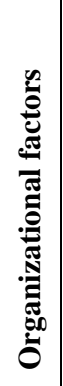 & 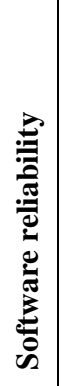 & 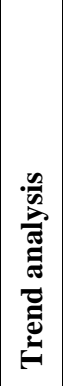 & 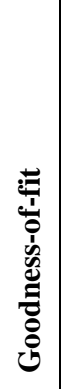 & 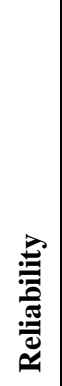 & 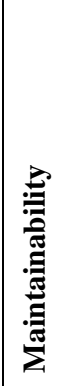 & 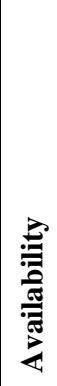 \\
\hline $\begin{array}{l}\text { Yazhou et al., 1995, } \\
\text { [51] }\end{array}$ & & & & & & & & & & & $\checkmark$ & & \\
\hline $\begin{array}{l}\text { Yazhou et al., 1995, } \\
\text { [52] }\end{array}$ & & & & & & & & & & $\checkmark$ & $\checkmark$ & & \\
\hline $\begin{array}{l}\text { Karyagina et al., 1998, } \\
\text { [53] }\end{array}$ & & & & & & & & & & & & $\checkmark$ & \\
\hline Wang et al., 1999, [25] & $\checkmark$ & & & & $\checkmark$ & & & & & & $\checkmark$ & & \\
\hline Wang et al., 1999, [26] & $\checkmark$ & & & & $\checkmark$ & & & & & $\checkmark$ & $\checkmark$ & & \\
\hline Sehgal et al., 2000, [54] & & & & & $\checkmark$ & & & & & & $\checkmark$ & & \\
\hline Dasic, P., 2001, [55] & & & & & & & & & & $\checkmark$ & $\checkmark$ & & \\
\hline Wang et al., 2001, [33] & $\checkmark$ & & $\checkmark$ & & & & & & & & $\checkmark$ & & \\
\hline Wang et al., 2001, [32] & & & & & $\checkmark$ & & & & & & $\checkmark$ & & \\
\hline Dai and Jia, 2001, [56] & & & & & $\checkmark$ & & & & & & $\checkmark$ & & \\
\hline Dai et al., 2003, [28] & & & & & & & & & & $\checkmark$ & $\checkmark$ & & \\
\hline Wang et al., 2003, [57] & & & & & & & & & & & $\checkmark$ & & \\
\hline $\begin{array}{l}\text { Jolly and Wadhwa, } \\
\text { 2004, [58] }\end{array}$ & & & & & & & & & & & $\checkmark$ & $\checkmark$ & $\checkmark$ \\
\hline Zhou et al., 2005, [29] & $\checkmark$ & $\checkmark$ & & & $\checkmark$ & & & & & & $\checkmark$ & & \\
\hline Zhang et al., 2007, [30] & $\checkmark$ & & & & & & & & & $\checkmark$ & $\checkmark$ & & \\
\hline $\begin{array}{l}\text { Lad and Kulkarni, } \\
\text { 2008, [59] }\end{array}$ & & & & & & & & & & & $\checkmark$ & $\checkmark$ & \\
\hline $\begin{array}{l}\text { Lad and Kulkarni, } \\
2010,[20]\end{array}$ & & & & & & & & & & & $\checkmark$ & $\checkmark$ & \\
\hline $\begin{array}{l}\text { Sung and Lee, 2011, } \\
\text { [66] }\end{array}$ & & & & & $\checkmark$ & & & & & & $\checkmark$ & & \\
\hline Yang et al., 2013, [27] & $\checkmark$ & & & & $\checkmark$ & & & & & $\checkmark$ & $\checkmark$ & $\checkmark$ & \\
\hline Yang et al., 2015, [60] & & & & & & & & & & & $\checkmark$ & & \\
\hline Chen et al., 2015, [61] & $\checkmark$ & & & & $\checkmark$ & & & & & $\checkmark$ & $\checkmark$ & $\checkmark$ & \\
\hline Yang et al., 2016, [62] & & $\checkmark$ & & & & & & & & & $\checkmark$ & & \\
\hline Li et al., 2016, [63] & & & & & & & & & & & $\checkmark$ & & \\
\hline Peng et al., 2016, [64] & & $\checkmark$ & & & & & & & & & $\checkmark$ & & \\
\hline $\begin{array}{l}\text { Patil and Kothavale, } \\
\text { 2018, [7] }\end{array}$ & $\checkmark$ & & & & $\checkmark$ & & & & & & $\checkmark$ & $\checkmark$ & \\
\hline Patil et al., 2018, [2] & $\checkmark$ & $\checkmark$ & $\checkmark$ & $\checkmark$ & & & & & $\checkmark$ & $\checkmark$ & $\checkmark$ & $\checkmark$ & $\checkmark$ \\
\hline
\end{tabular}


The literature survey shows that the existing data analysis frameworks need several tests to assess the trend in the data and obtain the best fit reliability distribution. It can also be seen that several studies and frameworks analyze the data using a specific reliability distribution such as exponential, Weibull, normal, and lognormal. There is a need to develop a generalized framework for modeling the failure and repair data. Most of the frameworks are applicable for the system's binary state and not Multi-State System (MSS). Several reliability analyses assume that the system has binary states (either working or failed). It is also essential to consider the system degraded states whenever necessary to get detailed failure characteristics and their associated impact on the system. The accuracy of the predicted reliability depends on the sample size, i.e., the amount of data available. There are very few papers describing the sample size selection for a known or unknown population. Therefore, it is necessary to include a sample size selection approach in the framework. The reliability of any system influenced by its four key elements: hardware, software, organizational, and human. Reliability and maintainability studies are often carried out using one or two elements, particularly hardware and software. Studies have shown that several incidents occur due to the mistake made by the human or policies implemented by the organization. Human and Organizational Factors (HOFs) significantly affect system reliability. Therefore, it is critical to identify and eliminate the failure and repair data affected by HOFs, often called anomalies.

This paper proposes a generalized framework for failure and repair data analysis addressing the key concerns of the existing frameworks. It is then integrated with the Markov chains, and an availability model is developed for the analysis of CNCMT. The reliability, maintainability, and availability characteristics of the CNCMT are estimated. The Steady-State Availability (SSA) of the CNCMT is estimated, and the sub-systems that are critical from a reliability and maintainability point of view are identified.

\section{Framework for TBF and TTR Data Analysis of CNCMTs}

Several TBF and TTR data analysis frameworks were developed for modeling and analysis of failure and repair data [11, 17, 18]. However, these data analysis frameworks are complex in nature and it is suggested to conduct a large number of tests for trend assessment and verifying goodness-of-fit. In this context, a simplified data analysis framework is developed by modifying the existing one to make it flexible, so that it can be applied for the analysis of the selected CNCMT with sufficient accuracy and with reduction of analysis duration.

The first step in reliability, maintainability, and availability modeling is system selection. Reliability modeling is a time-consuming and critical process and 
therefore, it is essential to understand and define the necessity. After defining the system, increase the understanding level of the system and divide the system into different sub-systems and components based on their functionality and dependency. Several systems have multi-state components or sub-systems. In this case, the Multi-State System (MSS) approach can be used for modeling otherwise binary state system analysis is preferred. In the MSS approach, a clear distinction between various degraded states is essential. In this view, the critical information can be collected from the available failure and repair data, and judgments of the experts.

The next step is to decide the appropriate methodology or technique for analyzing the data. Baye's technique can be used for reliability modeling if the available data is insufficient or incomplete, or there is no data. Data of other systems, subsystems, or components can be used for modeling the same. Furthermore, if sufficient data is not available, non-parametric methods can be applied for early reliability prediction of the system. However, reliability prediction with nonparametric methods is not accurate. It is used only at the preliminary stage of analysis. However, in critical systems, the required accuracy of the modeling and analysis is to be very high. In this situation, parametric methods are widely used. The present framework considers two stochastic processes 'as good as new (perfect repair)' and 'as bad as old (minimal repair)'. The framework uses only specific and required tests for trend analysis and estimation of goodness-of-fit.

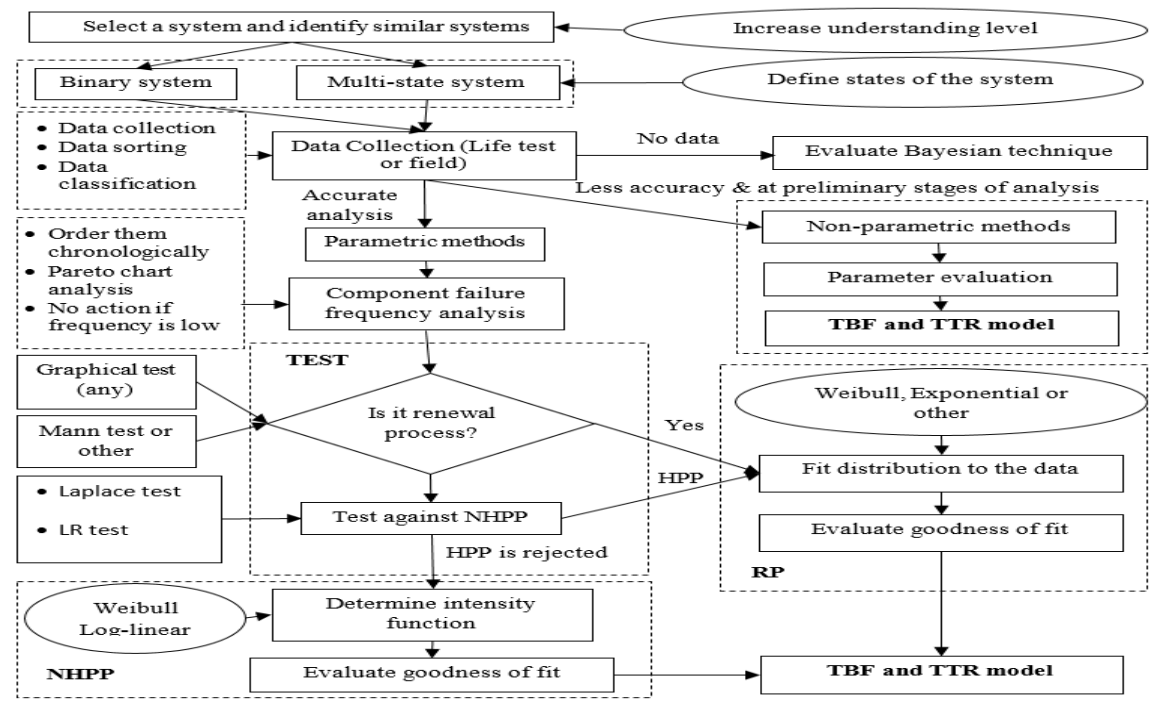

Figure 2

Generalized framework for the selection of TBF and TTR model [2, 11, 34]

Figure 2 shows a generalized framework used for the TBF and TTR data analysis of the CNCMT. The proposed framework is a simple way for reliability, 
maintainability, and availability predictors to appropriately evaluate the failure mechanisms and distinguish whether a renewable process or minimal repair process needs to be used. Graphical tests such as cumulative failure versus time, scatter plots of successive service lives, and analytical methods such as the Mann test are used for tests against RP. Methods such as Laplace, Lewis-Robinson, and military handbook are the most suitable for test against NHPP.

\section{Sample Size Selection for Reliability, Maintainability and Availability Analysis of CNCMTs}

This section attempts to select an appropriate sample (TBF and TTR data) of the CNCMT under consideration to predict the reliability and maintainability characteristics precisely. In this context, various terms such as the universe, population, and sample are defined.

The manufacturer, SPM Toold, Ichalkaranji, India, produces three models of CNCMT: $\mathrm{CNCMT}_{1}, \mathrm{CNCMT}_{2}$, and $\mathrm{CNCMT}_{3}$ with different production capacities. The group of all the CNCMTs $\left(\mathrm{CNCMT}_{1}, \mathrm{CNCMT}_{2}\right.$, and $\left.\mathrm{CNCMT}_{3}\right)$ is considered as the universe. The manufacturer told us that the $\mathrm{CNCMT}_{2}$ is the most popular and salable model, and they recommended we analyze the reliability of that model. Therefore, this paper uses the TBF and TTR data of $\mathrm{CNCMT}_{2}$. In this view, the group of all the $\mathrm{CNCMT}_{2}$ models produced is considered as population. Furthermore, the appropriate sample size can be defined as the number of $\mathrm{CNCMT}_{2}$ models and the amount of TBF and TTR data required for predicting the reliability, maintainability, and availability characteristics accurately. As the most significant step is to estimate the appropriate sample size (number of machines and the amount of TBF and TTR data) from the population. An attempt is made to select an appropriate sample size from the population and is as given below.

Table 4

Summary of sample size and data collection period for CNC assisted machine tools

\begin{tabular}{|l|c|c|}
\hline \multicolumn{1}{|c|}{ Authors } & Number of machine tools & $\begin{array}{c}\text { Data collection } \\
\text { period }\end{array}$ \\
\hline Keller et al., (1982), [1] & 35 & 3 years \\
\hline McGoldrick and Kullukt, (1986), [2] & Lathe 69+ NC 14 & 1 year \\
\hline Gupta and Somers, (1989), [3] & 05 types of CNC machines & 3 years \\
\hline Karyagina et al., (1995), [4] & 09 & --- \\
\hline Yazhou et al., (1995), [5] & 24 & 1 year \\
\hline Wang et al., (1999), [6] & 80 & 2 years \\
\hline Wang et al., (2001), [7] & 09 & --- \\
\hline Dai and Jia, (2001), [8] & 14 & 2 years \\
\hline
\end{tabular}




\begin{tabular}{|l|c|c|}
\hline \multicolumn{1}{|c|}{ Authors } & Number of machine tools & $\begin{array}{c}\text { Data collection } \\
\text { period }\end{array}$ \\
\hline Jolly and Wadhwa, (2004), [9] & 04 & 3 years \\
\hline Wang et al., (2013), [10] & 12 & 5 years \\
\hline Yang et al., (2015), [10] & --- & 3000 hours \\
\hline Waghmode and Patil, (2016), [65] & 10 & 2 years \\
\hline Present work & 50 & 5 years \\
\hline
\end{tabular}

The central limit theorem is widely used in statistical inference. It explains the relationship between the shape of the population distribution and the sampling distribution. It reveals that if the sample size $(n)$ is greater than 30 , the shape of the sampling distribution takes a shape like a normal distribution [35]. Therefore, the central limit theorem reveals that a sample size greater than 30 could be used. However, the validity of the central limit theorem is verified by using the sample size used in the literature for CNCMT's reliability analysis. The summary of sample size (number of CNCMTs) and the data collection period taken for the reliability analysis of CNC assisted machine tools by various researchers is shown in Table 4. It shows that the required TBF and TTR data of nearly $25 \mathrm{CNC}$ assisted machine tools over almost 2 years has to be collected. The last row of Table 4 gives the number of $\mathrm{CNCMT}_{2}$ models and the TBF and TTR data collection period for the present work carried out. Furthermore, the reliability characteristics of the $\mathrm{CNCMT}_{2}$ are estimated using the methodology presented in Figure 2 for different sample sizes and given in Table 5. It is observed that Weibull $3 \mathrm{P}$ is the best-fit distribution for the $\mathrm{CNCMT}_{2}$. The distribution parameters such as shape parameter $(\beta)$, scale parameter $(\theta)$, and location parameter $(\gamma)$ are converging as the sample size increases.

Table 5

Variation in reliability characteristics for Weibull 3P distribution

\begin{tabular}{|c|c|c|c|c|c|c|c|}
\hline $\begin{array}{c}\text { Sample } \\
\text { size }\end{array}$ & $\begin{array}{c}\text { No of } \\
\text { Machines }\end{array}$ & $\boldsymbol{\beta}$ & $\boldsymbol{\theta}$ & $\boldsymbol{\gamma}$ & MTBF & $\begin{array}{c}\text { Change } \\
\text { in } \\
\text { MTBF }\end{array}$ & $\begin{array}{c}\% \\
\text { Deviation }\end{array}$ \\
\hline 112 & 5 & 1.0388 & 2177 & 10.41 & 2155 & & \\
\hline 235 & 10 & 1.0087 & 2067 & 0.42 & 2060 & -95 & -4.61 \\
\hline 338 & 15 & 0.9046 & 2062 & 11.54 & 2175 & 115 & 5.29 \\
\hline 466 & 20 & 0.8717 & 1937 & 12.93 & 2089 & -86 & -4.12 \\
\hline 601 & 25 & 0.9082 & 1902 & 11.05 & 2003 & -86 & -4.29 \\
\hline 693 & 30 & 0.8993 & 1908 & 12.18 & 2021 & 18 & 0.89 \\
\hline 771 & 35 & 0.8993 & 1880 & 13.08 & 1992 & -29 & -1.46 \\
\hline 846 & 40 & 0.8966 & 1903 & 14.16 & 2020 & 28 & 1.39 \\
\hline 928 & 45 & 0.906 & 1898 & 13.75 & 2004 & -16 & -0.80 \\
\hline 959 & 50 & 0.909 & 1895 & 13.23 & 1996 & -8 & -0.40 \\
\hline
\end{tabular}


Table 5 (continued)

Variation in reliability characteristics for Weibull 3P distribution

\begin{tabular}{|c|c|c|}
\hline $\boldsymbol{\sigma}$ & Change in $\boldsymbol{\sigma}$ & \% Deviation \\
\hline 2172 & & -5.07 \\
\hline 2067 & -105 & -0.25 \\
\hline 2062 & -5 & -6.65 \\
\hline 1933 & -129 & -1.33 \\
\hline 1908 & -25 & 0.32 \\
\hline 1914 & 6 & -1.49 \\
\hline 1886 & -28 & 0.83 \\
\hline 1902 & 16 & 0.24 \\
\hline 1906 & 5 & -0.34 \\
\hline 1900 & -6 & \\
\hline
\end{tabular}

Similarly, reliability characteristics such as Mean-Time-Between-Failure (MTBF) and standard deviation $(\sigma)$ are also converging with an increase in sample size. The percentage deviation in MTBF and standard deviation $(\sigma)$ is less than $1 \%$ for $959 \mathrm{TBF}$ data. It clearly shows that a sample size (959 TBF data) collected from $50 \mathrm{CNCMT}_{2}$ models is sufficient for reliability analysis. The shape parameter of the $\mathrm{CNCMT}_{2}$ is nearly equal to 1 and reveals that the failure rate of the $\mathrm{CNCMT}_{2}$ is almost constant. Therefore, exponential distribution can be used to estimate and predict reliability characteristics precisely. The value of the location parameter (assured life) is very small, i.e., 13.23 hours, which is very small, and therefore, the Weibull 2P distribution can also be used for predicting reliability characteristics instead of the Weibull 3P distribution. The MTBF of the $\mathrm{CNCMT}_{2}$ is nearly 2000 hrs. It shows that almost four to five failures of the $\mathrm{CNCMT}_{2}$ will occur per year.

Furthermore, one more attempt is made to estimate the required sample size when the population's size is unknown. Equation (1) is used for calculating the sample size when the population is unknown [35]. The analysis is required to be carried out very accurately. Therefore, the standard variate $(z)$ is taken as 1.96 for a $95 \%$ confidence level. The standard deviation $(\sigma)$ of the population and sample is assumed to be the same and is taken as $1900 \mathrm{hrs}$ (see Table 5). The acceptable error (e), i.e., precision is taken as $\pm 190 \mathrm{hrs}$ ( $10 \%$ of the population standard deviation). Therefore, the required sample size (TBF data) for the unknown population is given as follows:

$$
n=\frac{z^{2} \times \sigma^{2}}{e^{2}}=\frac{1.96^{2} \times 1900^{2}}{190^{2}}=384.16 \cong 385
$$

The required sample size is 385 . The present study uses 959 TBF and TTR data of 50 CNCMTs operated in similar environmental conditions that are appropriate, and the sampling distribution of the CNCMT represents the distribution of the 
population of $\mathrm{CNCMT}_{2}$. In this view, the reliability, maintainability, and availability analysis is carried out based on the following assumptions:

- Working temperature varies from $0^{\circ}$ to $50^{\circ} \mathrm{C}$.

- Relative humidity is less than $75 \%$.

- Vibration level during the transportation is $3.5 \mathrm{G}$ or less.

- Vibration level during operation is $0.5 \mathrm{G}$ or less.

- Foundation precision level graduated to $0.02 / 0.05 \mathrm{~mm} / \mathrm{m}$.

- Capacity of the foundation capacity is more than $4000 \mathrm{~kg}$.

- Spindle working temperature varies between $-60^{\circ} \mathrm{C}$ to $+130^{\circ} \mathrm{C}$.

- Maximum spindle speed is 5,500 rpm.

- Recommended lubricant, coolant, and hydraulic oil are used.

- Lubrication of various parts is done at suggested intervals with the suggested quantity.

- Hydraulic oil and coolant is replaced at regular intervals.

- Failed component/sub-system is replaced with the same and new component.

- Maintenance activities are carried out by using prescribed procedures.

\section{Steady-state Availability Analysis of CNCMT}

Availability analysis can be used to identify critical, sub-critical components/ equipment/sub-system of the CNCMT from the reliability and maintainability point of view. The CNCMT's availability is significantly influenced by the subsystem's failure and repair rates. The developed data analysis framework is used to estimate Steady-State Availability (SSA), and the effects of sub-system's failure and repair rates on the SSA of the CNCMT are investigated. For this purpose, the availability analysis of the CNCMT under consideration is presented using the Markov chain.

\subsection{System Description for Markov Modeling}

The fourteen sub-systems of the CNCMT, and notations for the operational and failed states, failure, and repair rates are defined and given in Table 6 . These codes and notations are used for modeling the CNCMT using Markov chains. The availability modeling and analysis are carried out under the following assumptions:

- Sub-system's failure rates and repair rates are constant

- The failures and repairs are statistically independent and identically distributed (iid). 
- Only one failure occurs at a time.

- After repair action, the state of the sub-system is assumed to be as good as new (renewal approach).

Table 6

Description for modeling of the CNCMT using Markov chains

\begin{tabular}{|c|c|c|c|c|c|}
\hline \multirow{2}{*}{$\begin{array}{l}\text { Sr. } \\
\text { No. }\end{array}$} & \multirow[b]{2}{*}{ Sub-system } & \multicolumn{2}{|c|}{ Code } & \multirow{2}{*}{$\begin{array}{c}\text { Failure } \\
\text { rate } \\
\left(\lambda_{i}\right)\end{array}$} & \multirow{2}{*}{$\begin{array}{c}\text { Repair } \\
\text { rate } \\
\left(\mu_{i}\right)\end{array}$} \\
\hline & & $\begin{array}{l}\text { Operational } \\
\text { state }\end{array}$ & $\begin{array}{c}\text { Failed } \\
\text { state }\end{array}$ & & \\
\hline 1 & Main Transmission (MT) & $\mathrm{A}$ & $\mathrm{a}$ & $\lambda_{1}$ & $\mu_{I}$ \\
\hline 2 & Spindle Sub-system (SS) & B & $\mathrm{b}$ & $\lambda_{2}$ & $\mu_{2}$ \\
\hline 3 & Chuck Sub-system (ChS) & $\mathrm{C}$ & $\mathrm{c}$ & $\lambda_{3}$ & $\mu_{3}$ \\
\hline 4 & $\begin{array}{l}X \text { and } Z \text { Axis Sub-system } \\
(\mathrm{XZAS})\end{array}$ & $\mathrm{D}$ & $d$ & $\lambda_{4}$ & $\mu_{4}$ \\
\hline 5 & Turret Sub-system (TS) & $\mathrm{E}$ & $\mathrm{e}$ & $\lambda_{5}$ & $\mu_{5}$ \\
\hline 6 & Cooling Sub-system (CS) & $\mathrm{F}$ & $\mathrm{f}$ & $\lambda_{6}$ & $\mu_{6}$ \\
\hline 7 & $\begin{array}{l}\text { Lubrication } \quad \text { Sub-system } \\
\text { (LS) }\end{array}$ & G & $\mathrm{g}$ & $\lambda_{7}$ & $\mu_{7}$ \\
\hline 8 & Hydraulic Sub-system (HS) & $\mathrm{H}$ & $\mathrm{h}$ & $\lambda_{8}$ & $\mu_{8}$ \\
\hline 9 & CNC Sub-system (CNCS) & I & $\mathrm{i}$ & $\lambda_{9}$ & $\mu_{9}$ \\
\hline 10 & $\begin{array}{l}\text { Electrical and Electronic } \\
\text { Sub-system (EES) }\end{array}$ & $\mathrm{J}$ & $\mathrm{j}$ & $\lambda_{10}$ & $\mu_{10}$ \\
\hline 11 & Swarf Conveyor (SC) & $\mathrm{K}$ & $\mathrm{k}$ & $\lambda_{11}$ & $\mu_{11}$ \\
\hline 12 & Pneumatic Sub-system (PS) & $\mathrm{L}$ & 1 & $\lambda_{12}$ & $\mu_{12}$ \\
\hline 13 & $\begin{array}{l}\text { Tail-stock } \quad \text { Sub-system } \\
\text { (TSS) }\end{array}$ & M & $\mathrm{m}$ & $\lambda_{13}$ & $\mu_{13}$ \\
\hline 14 & Other Sub-system (OS) & $\mathrm{N}$ & $\mathrm{n}$ & $\lambda_{14}$ & $\mu_{14}$ \\
\hline
\end{tabular}

\subsection{Development of Transition Diagram and Mathematical Modeling}

Figure 3 gives the notations and symbols used for representing the states of the subsystems. Figure 4 shows the transition diagram or state-space model and the logical representation of CNCMT's failures. The transition diagram defines the transitions of sub-system's one state to another (operational to failed and failed to operational). Here, $P_{i}(t)$ is the probability that at any time $t$ the system is in the $i$ th state and $(\cdot)^{\prime}$ is the derivative with respect to time $t$. 


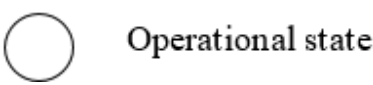

\section{Failed state}

Figure 3

Used symbols

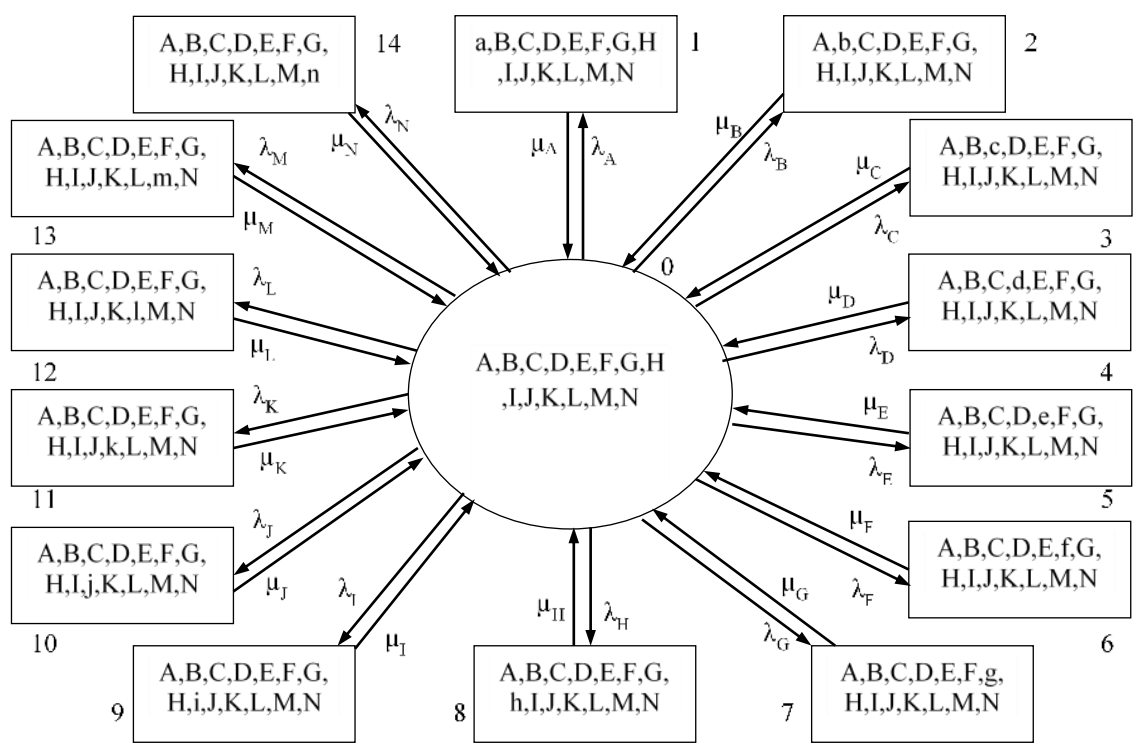

Figure 4

Transition diagram of CNCMT using Markov chains

The laws of probability and transition diagram are used, and equations (2)-(16) are developed. The steady state availability equation for the CNCMT is then developed as follows:

$P_{0}^{\prime}(t)$

$+\left(\lambda_{1}+\lambda_{2}+\lambda_{3}+\lambda_{4}+\lambda_{5}+\lambda_{6}+\lambda_{7}+\lambda_{8}+\lambda_{9}+\lambda_{10}+\lambda_{11}+\lambda_{12}+\lambda_{13}\right.$

$\left.+\lambda_{14}\right) P_{0}(t)$

$=\mu_{1} P_{1}(t)+\mu_{2} P_{2}(t)+\mu_{3} P_{3}(t)+\mu_{4} P_{4}(t)+\mu_{5} P_{5}(t)+\mu_{6} P_{6}(t)+\mu_{7} P_{7}(t)$

$+\mu_{8} P_{8}(t)+\mu_{9} P_{9}(t)+\mu_{10} P_{10}(t)+\mu_{11} P_{11}(t)+\mu_{12} P_{12}(t)+\mu_{13} P_{13}(t)$

$+\mu_{14} P_{14}(t)$

$$
\begin{aligned}
& P_{1}(t)+\mu_{1} P_{1}(t)=\lambda_{1} P_{0}(t) \\
& P_{2}^{\prime}(t)+\mu_{2} P_{2}(t)=\lambda_{2} P_{0}(t) \\
& P_{3}^{\prime}(t)+\mu_{3} P_{3}(t)=\lambda_{3} P_{0}(t) \\
& P_{4}^{\prime}(t)+\mu_{4} P_{4}(t)=\lambda_{4} P_{0}(t)
\end{aligned}
$$




$$
\begin{aligned}
& P_{5}^{\prime}(t)+\mu_{5} P_{5}(t)=\lambda_{5} P_{0}(t) \\
& P_{6}^{\prime}(t)+\mu_{6} P_{6}(t)=\lambda_{6} P_{0}(t) \\
& P_{7}^{\prime}(t)+\mu_{7} P_{7}(t)=\lambda_{7} P_{0}(t) \\
& P_{8}^{\prime}(t)+\mu_{8} P_{8}(t)=\lambda_{8} P_{0}(t) \\
& P_{9}^{\prime}(t)+\mu_{9} P_{9}(t)=\lambda_{9} P_{0}(t) \\
& P_{10}^{\prime}(t)+\mu_{10} P_{10}(t)=\lambda_{10} P_{0}(t) \\
& P_{11}^{\prime}(t)+\mu_{11} P_{11}(t)=\lambda_{11} P_{0}(t) \\
& P_{12}^{\prime}(t)+\mu_{12} P_{12}(t)=\lambda_{12} P_{0}(t) \\
& P_{13}^{\prime}(t)+\mu_{13} P_{13}(t)=\lambda_{13} P_{0}(t) \\
& P_{14}^{\prime}(t)+\mu_{14} P_{14}(t)=\lambda_{14} P_{0}(t)
\end{aligned}
$$

The initial conditions are: $t=0, P_{i}(t)=1$ for $i=0$, otherwise $P_{i}(t)=0$. The life of the CNCMT is approximately taken as 12 years. Therefore, for such a long duration of time, the SSA of the CNCMT can be calculated by setting $\frac{d}{d t} \rightarrow 0$ and $t \rightarrow \infty$, into all the differential (Equations (2)-(16)). Thus, Equations ((17)(31)) give the limiting state probabilities:

$$
\begin{aligned}
\left(\lambda_{1}+\lambda_{2}+\lambda_{3}+\right. & \left.\lambda_{4}+\lambda_{5}+\lambda_{6}+\lambda_{7}+\lambda_{8}+\lambda_{9}+\lambda_{10}+\lambda_{11}+\lambda_{12}+\lambda_{13}+\lambda_{14}\right) P_{0} \\
& =\mu_{1} P_{1}+\mu_{2} P_{2}+\mu_{3} P_{3}+\mu_{4} P_{4}+\mu_{5} P_{5}+\mu_{6} P_{6}+\mu_{7} P_{7}+\mu_{8} P_{8} \\
& +\mu_{9} P_{9}+\mu_{10} P_{10}+\mu_{11} P_{11}+\mu_{12} P_{12}+\mu_{13} P_{13} \\
& +\mu_{14} P_{14} \\
& \\
\mu_{1} P_{1}= & \lambda_{1} P_{0} \\
\mu_{2} P_{2}= & \lambda_{2} P_{0} \\
\mu_{3} P_{3}= & \lambda_{3} P_{0} \\
\mu_{4} P_{4}= & \lambda_{4} P_{0} \\
\mu_{5} P_{5}= & \lambda_{5} P_{0} \\
\mu_{6} P_{6}= & \lambda_{6} P_{0} \\
\mu_{7} P_{7}= & \lambda_{7} P_{0} \\
\mu_{8} P_{8}= & \lambda_{8} P_{0} \\
\mu_{9} P_{9}= & \lambda_{9} P_{0} \\
\mu_{10} P_{10}= & \lambda_{10} P_{0} \\
\mu_{11} P_{11}= & \lambda_{11} P_{0}
\end{aligned}
$$




$$
\begin{aligned}
& \mu_{12} P_{12}=\lambda_{12} P_{0} \\
& \mu_{13} P_{13}=\lambda_{13} P_{0} \\
& \mu_{14} P_{14}=\lambda_{14} P_{0}
\end{aligned}
$$

For analysis purpose and simplification, the values $\left(P_{1}, P_{2}, P_{3} \ldots, P_{14}\right)$ are respectively introduced in Equations (17)-(31):

$$
\begin{aligned}
P_{1}=K_{1} P_{0} ; P_{2} & =K_{2} P_{0} ; P_{3}=K_{3} P_{0} ; P_{4}=K_{4} P_{0} ; P_{5}=K_{5} P_{0} ; P_{6}=K_{6} P_{0} ; P_{7} \\
& =K_{7} P_{0} ; P_{8}=K_{8} P_{0} ; P_{9}=K_{9} P_{0} ; P_{10}=K_{10} P_{0} ; P_{11} \\
& =K_{11} P_{0} ; P_{12}=K_{12} P_{0} ; P_{13}=K_{13} P_{0} ; P_{14}=K_{14} P_{0} ; P_{7} \\
& =K_{7} P_{0} ; P_{8}=K_{8} P_{0} ;
\end{aligned}
$$

For normalized conditions, the sum of all the probabilities is equal to one:

$$
\sum_{i=0}^{15} P_{i}=1
$$

The sum of all the operating state probabilities gives the model for the SSA of the CNCMT as given as follows:

$$
\begin{aligned}
& S S A=P_{0}=\left[1+K_{1}+K_{2}+K_{3}+K_{4}+K_{5}+K_{6}+K_{7}+K_{8}+K_{9}+K_{10}+K_{11}\right. \\
& \left.+K_{12}+K_{13}+K_{14}\right]^{-1} \\
& \therefore P_{0}=[1+A]^{-1}
\end{aligned}
$$

where,

$$
A=K_{1}+K_{2}+K_{3}+K_{4}+K_{5}+K_{6}+K_{7}+K_{8}+K_{9}+K_{10}+K_{11}+K_{12}+K_{13}+
$$

\subsection{Results and Analysis}

This Section illustrates the results with an analysis of the developed SSA model of the CNCMT given by Equation (33). The influence of sub-system's failure rate and repair rates on the SSA of the CNCMT is also analyzed. Table 7 reports the sub-system's failure rate and repair rate per hour that is generally affected by various factors such as operating conditions, maintenance procedures, errors during maintenance, and entry of data in the maintenance register. Sub-system's failure and repair rates are varied by $\pm 5 \%$ and $\pm 10 \%$ to study its effect on the SSA of the CNCMT.

Figure 5 shows the effect of variation of the failure rates of the sub-systems on the availability of the CNCMT. In this case, the repair rates of the sub-systems are kept as it is to identify the severe sub-system of the CNCMT from a reliability point of view. It is seen that the SSA of the CNCMT gives a range of failure rates 
of the sub-systems excluding TS that varies from 0.9053 to 0.9073 (change in $\mathrm{SSA}=0.221 \%)$.

Table 7

Failure rate $(\lambda)$ and repair rate $(\mu)$ of CNCMT's sub-systems

\begin{tabular}{|c|l|c|c|}
\hline $\begin{array}{c}\text { Sr. } \\
\text { No. }\end{array}$ & \multicolumn{1}{|c|}{ Equipment Name } & $\begin{array}{c}\text { Failure Rate }\left(\lambda_{i}\right) \\
\text { per hour }\end{array}$ & $\begin{array}{c}\text { Repair Rate }\left(\boldsymbol{\mu}_{\boldsymbol{i}}\right) \\
\text { per hour }\end{array}$ \\
\hline 1 & Main Transmission (MT) & 0.000434028 & 0.263157895 \\
\hline 2 & Spindle Sub-system (SS) & 0.000262467 & 0.02173913 \\
\hline 3 & Chuck Sub-system (ChS) & 0.000442478 & 0.142857143 \\
\hline 4 & $\begin{array}{l}X \quad \text { and } \text { Z Axis Sub-system } \\
(\text { XZAS) }\end{array}$ & 0.000338409 & 0.029411765 \\
\hline 5 & Turret Sub-system (TS) & 0.000576037 & 0.0625 \\
\hline 6 & Cooling Sub-system (CS) & 0.000516529 & 0.27027027 \\
\hline 7 & Lubrication Sub-system (LS) & 0.00035727 & 0.011764706 \\
\hline 8 & Hydraulic Sub-system (HS) & 0.000428449 & 0.263157895 \\
\hline 9 & CNC Sub-system (CNCS) & 0.000485201 & 0.080645161 \\
\hline 10 & $\begin{array}{l}\text { Electrical and Electronic Sub- } \\
\text { system (EES) }\end{array}$ & 0.000483559 & 0.095238095 \\
\hline 11 & Swarf Conveyor (SC) & 0.000217817 & 0.333333333 \\
\hline 12 & Pneumatic Sub-system (PS) & 0.000341997 & 0.5 \\
\hline 13 & Tail-stock Sub-system (TSS) & 0.000119904 & 0.25 \\
\hline 14 & Other Sub-system (OS) & 0.000295858 & 0.434782609 \\
\hline
\end{tabular}

However, as the failure rate of the TS increases from 0.010588235 to 0.012941177 , the SSA of the CNCMT decreases from 0.9111 to 0.9016 (change in SSA $=1.042 \%$ ). Therefore, it can be seen that the SSA of the CNCMT is mostly influenced by the failure rate TS. Furthermore, the failure rate of the XZAS also affects the SSA of the CNCMT to a certain extent.

Figure 6 shows the effect of the variation of the repair rates of sub-systems on the SSA of the CNCMT. Here, the failure rates of all the sub-systems are kept as it is to identify the severe sub-system of the CNCMT from a maintainability point of view. It is observed that the SSA of the CNCMT for the given range of repair rates of the sub-systems excluding LS varies from 0.9052 to 0.9072 (change in SSA = $0.22 \%$ ). However, as the repair rate of LS improves from 0.010588235 to 0.012941177 , the SSA of the CNCMT increases from 0.9019 to 0.91 (change in SSA $=0.90 \%$ ). Therefore, it can be concluded that the repair rate of LS has the highest effect on the SSA of the CNCMT. Furthermore, XZAS and TS also affect the SSA of the CNCMT to a certain extent. 


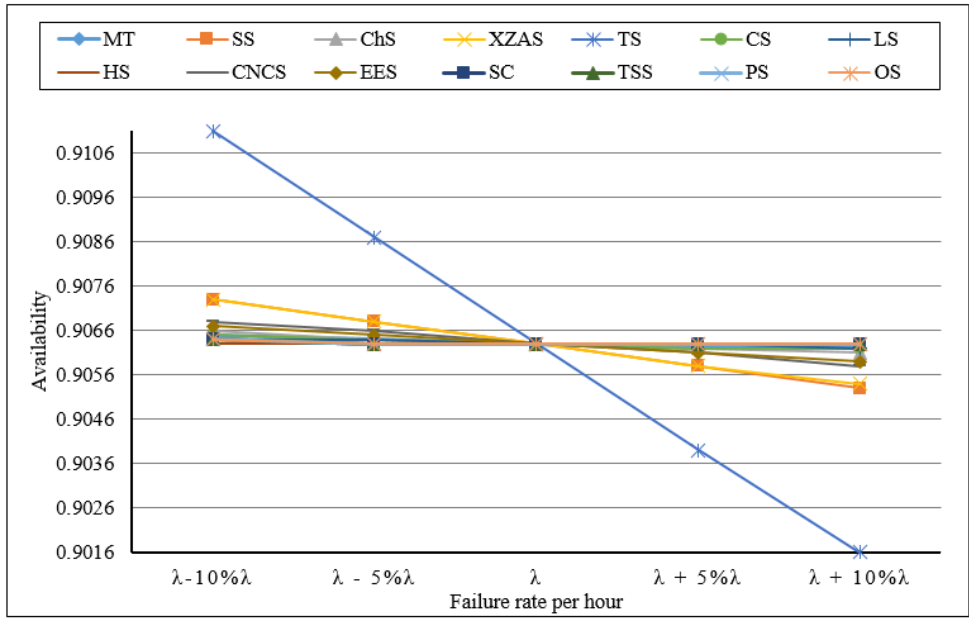

Figure 5

Effect of sub-system's failure rate on the SSA of the CNCMT

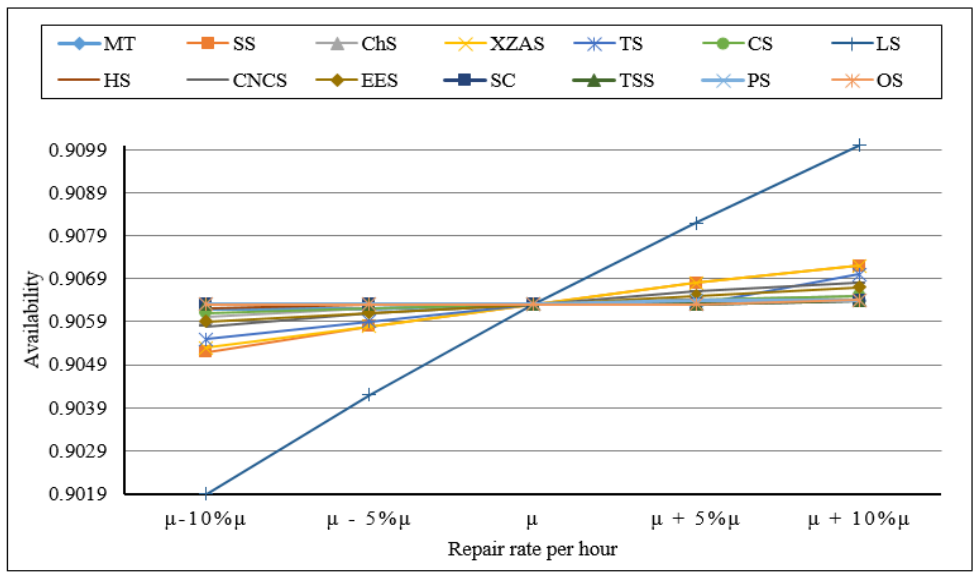

Figure 6

Effect of sub-system's repair rate on the SSA of the CNCMT

The effect of variation of sub-systems failure and repair rates on the SSA of the CNCMT is also presented in Table 8 and Figure 7. It is observed that the SSA of the CNCMT is $0.9063(90.63 \%)$. It varies from 0.922 for minimum failure rate and maximum repair rate to 0.8882 for maximum failure rate and minimum repair rate (change in SSA $=3.8055 \%$ ). The SSA matrix of the CNCMT is given in Table 8 . This availability variation is greatly influenced due to the considerable variation in the failure rate of TS and repair rate of LS. The SSA of CNCMT can be improved to a large extent by improving the failure rate of TS and repair rate of LS. The failure and repair rates of other sub-systems can also be improved to maximize the SSA of the CNCMT. 


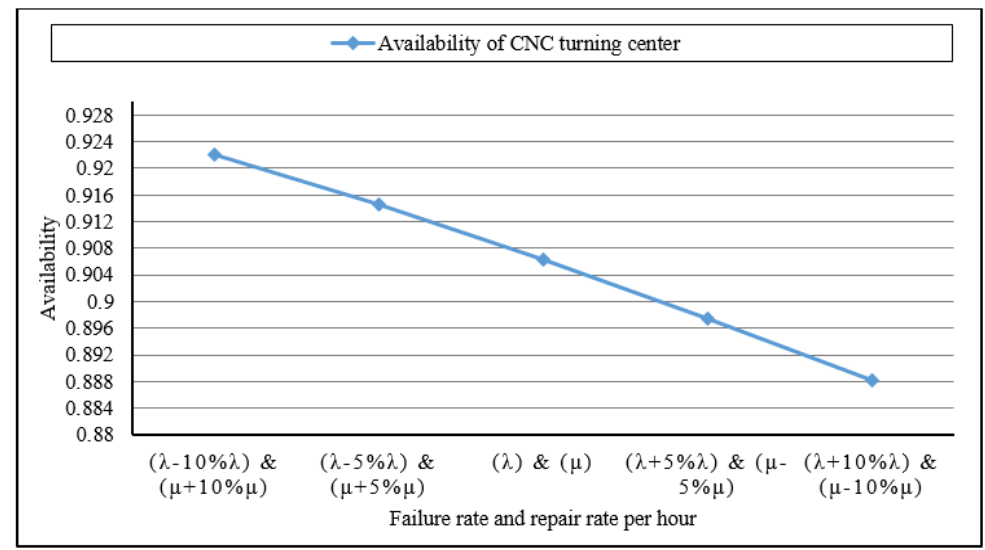

Figure 7

Effect of sub-system's failure and repair rates on the SSA of the CNCMT

Table 8

Availability matrix of CNCMT

\begin{tabular}{|c|c|c|c|c|c|}
\hline$\mu_{\mu_{i}} \lambda_{i}$ & $\lambda_{i}-10 \% \lambda_{\mathrm{i}}$ & $\lambda_{i}-5 \% \lambda_{i}$ & $\lambda_{i}$ & $\lambda_{i}+5 \% \lambda_{i}$ & $\lambda_{i}+10 \% \lambda_{i}$ \\
\hline$\mu_{i}-10 \% \mu_{\mathrm{i}}$ & 0.9063 & -- & -- & -- & 0.8882 \\
\hline$\mu_{i}-5 \% \mu_{\mathrm{i}}$ & -- & 0.9063 & -- & 0.8975 & -- \\
\hline$\mu_{i}$ & -- & -- & 0.9063 & -- & -- \\
\hline$\mu_{i}+5 \% \mu_{i}$ & -- & 0.9145 & -- & 0.9063 & -- \\
\hline$\mu_{i}+10 \% \mu_{i}$ & 0.9220 & -- & -- & -- & 0.9063 \\
\hline
\end{tabular}

\section{Conclusions}

Reliability, maintainability, and availability modeling and analysis are the integral parts of the design of any Computerized Numerical Control Machine Tool (CNCMT). This paper aimed to investigate the steady-state availability of a typical CNCMT using a developed TBF and TTR data analysis framework. The results obtained from reliability analysis show that the failure rate of the CNCMT is almost constant as the value of shape parameter $(\beta)$ is very close to 1 . The system MTBF is almost 2000 hours, which means that nearly four failures of the CNCMT will occur per year. CNC Sub-system (CNCS), Chuck Sub-system (ChS), Electrical and Electronic Sub-system (EES), Hydraulic Sub-system (HS), Main Transmission (MT), Turret Sub-system (TS) and $X$ and $Z$-axis Sub-system (XZAS) are the critical sub-systems of the CNCMT from a reliability perspective. Lubrication Sub-system (LS), Spindle Sub-system (SS), and XZAS are the subsystems that require considerable time from a maintenance perspective. The SSA of the CNCMT is estimated to be 0.9063 (90.63\%). It varies from 0.922 to 0.8882 (change in SSA $=3.8055 \%$ ) for $90 \%$ confidence level. This variation in the availability value is due to the large variation in the failure rate of TS and repair 
rate of LS. Therefore, it is concluded that the SSA of the CNCMT is significantly affected by the repair rate of the LS and the failure rate of the TS. This is useful in deciding the optimum values of failure and repair rates of these sub-systems for maximum availability. The results of reliability, maintainability, and availability analysis can be used further to develop the life cycle costing model of the CNCMT. Future works will be devoted to the development of a dynamic reliability model for the CNCMTs.

\section{References}

[1] A. A. Petunin and P. A. Chentsov, "Routing in CNC cutting machines: Engineering constraints," Acta Politechnica Hungarica, Vol. 17, No. 8, pp. $165-177,2020$

[2] R. B. Patil, B. S. Kothavale and L. Y. Waghmode, "Selection of time-tofailure model for computerized numerical control turning center based on the assessment of trends in maintenance data," Journal of Risk and Reliability, Vol. 233, pp. 105-117, 2018

[3] C. Duan, V. Makis and C. Deng, "A two-level Bayesian early fault detection for mechanical equipment subject to dependent failure modes," Reliability Engineering and System Safety, Vol. 193, p. 106676, 2020

[4] H. W. Lo, J. J. H. Liou, C. N. Huang and Y. C. Chuang, "A novel failure mode and effect analysis model for machine tool risk analysis," Reliability Engineering and System Safety, Vol. 183, pp. 173-183, 2019

[5] M. A. Mellal and E. J. Williams, "Parameter optimization of advanced machining processes using cuckoo optimization algorithm and hoopoe heuristic," Journal of Intelligent Manufacturing, Vol. 27, No. 5, pp. 927942, 2016

[6] M. A. Mellal and E. J. Williams, "Total production time minimization of a multi-pass milling process via cuckoo optimization algorithm," The International Journal of Advanced Manufacturing Technology, Vol. 87, No. 1, pp. 747-754, 2016

[7] R. B. Patil and B. S. Kothavale, "Failure Modes and Effects Analysis (FMEA) of Computerized Numerical Control (CNC) Turning Center," International review of mechanical engineering, Vol. 12, No. 1, pp. 78-87, 2018

[8] B. Jeon, J. S. Yoon, J. Um and S. H. Suh, "The architecture development of Industry 4.0 compliant smart machine tool system (SMTS)," Journal of Intelligent Manufacturing, Vol. 31, pp. 1837-1859, 2020

[9] A. Z. Keller, R. R. Kamath and U. D. Perera, "Reliability analysis of CNC machine tools," Reliability engineering, Vol. 3, No. 6, pp. 449-473, 1982 
[10] A. V. Ferris-Prabhu and N. D. Lubart, "Reliability analysis for simple systems," Microelectronics and reliability, Vol. 15, No. 6, pp. 555-560, 1976

[11] H. Ascher and H. Feingold, Repairable systems reliability: modeling, inference, misconceptions and their causes, New York: Maecel Dekker, 1984

[12] A. A. Abdel-Ghaly, P. Y. Chan and B. Littlewood, "Evaluation of competing software reliability prediction," IEEE transactions on software engineering, Vol. 12, No. 9, pp. 950-967, 1986

[13] U. Kumar, B. Klefsjo and S. Granholm, "Reliability investigation for a fleet of load haul dump machines in a Swedish mine," Reliability engineering and system safety, Vol. 26, No. 4, pp. 341-361, 1989

[14] L. H. Crow, "Evaluating the reliability of repairable systems," in Proceedings of annual reliability and maintainability symposium, Los Angeles, USA, 1990

[15] H. G. Pulido, V. A. Torres and J. A. Christen, "A practical method for obtaining prior distributions in reliability," IEEE transactions on reliability, Vol. 54, No. 2, pp. 262-269, 2005

[16] J. S. Kim and B. J. Yum, "Selection between Weibull and lognormal distributions: a comparative simulation study," Computational statistics and data analysis, Vol. 53, pp. 477-485, 2008

[17] J. Barabady and U. Kumar, "Reliability analysis of mining equipment: a case study of crushing plant at Jajarm Bauxite mine in Iran," Reliability engineering and system safety, Vol. 93, pp. 647-653, 2008

[18] D. M. Louit, R. Pascual and A. K. S. Jardine, "A practical procedure for the selection of time-to-failure models based on the assessment of trends in maintenance data," Reliability engineering and system safety, Vol. 94, No. 10, pp. 1618-1628, 2009

[19] A. Regettieri, R. Manzini and D. Battini, "Estimating reliability characteristics in the presence of censored data: a case study in a light commercial vehicle manufacturing system," Reliability engineering and system safety, Vol. 95, pp. 1093-1102, 2010

[20] B. L. Lad and M. S. Kulkarni, "A parameter estimation method for machine tool reliability analysis using expert judgement," International journal data analysis techniques and strategies, Vol. 2, No. 2, pp. 155-169, 2010

[21] J. F. Castet and J. H. Saleh, "Beyond reliability, multi-state failure analysis of satellite sub-systems: a statistical approach," Reliability engineering and system safety, Vol. 95, pp. 311-322, 2010 
[22] A. Barabadi, "Reliability model selection and validation using Weibull probability plot - a case study," Electric power research, Vol. 101, pp. 96101,2013

[23] A. Barabadi, J. Barabady and T. Markeset, "Application of reliability models with covariates in spare part prediction and optimization - a case study," Reliability engineering and system safety, Vol. 123, pp. 1-7, 2014

[24] S. Bobrowski, H. Chen, M. Doring, U. Jensen and W. Schinkothe, "Estimation of the lifetime distribution of mechatronic systems in the presence of a covariate: a comparison among parametric, semi-parametric and non-parametric models," Reliability engineering and system safety, Vol. 139, pp. 105-112, 2015

[25] Y. Wang, Y. Jia, J. Yu and S. Yi, "Field failure database of CNC lathes," International journal of quality and reliability management, Vol. 16, No. 4, pp. 330-340, 1999

[26] Y. Wang, Y. Jia, J. Yu, Y. Zheng and S. Yi, "Failure probabilistic model of CNC lathes," Reliability engineering and system safety, Vol. 65, No. 3, pp. 307-314, 1999

[27] Z. Yang, C. Chen, F. Chen, Q. Hao and B. Xu, "Reliability analysis of machining center based on the field data," Maintenance and reliability, Vol. 15, No. 2, pp. 147-155, 2013

[28] Y. Dai, Y. Zhou and Y. Jia, "Distribution of time between failures of machining center based on type I censored data," Reliability engineering and system safety, Vol. 79, No. 3, pp. 377-379, 2003

[29] G. Zhou, Y. Jia, H. Zheng and G. Wang, "A new single-sample failure model and its application to a special CNC system," International journal of quality and reliability management, Vol. 22, No. 4, pp. 421-430, 2005

[30] H. Zhang, Z. Jia and G. Zhou, "Time between failures model and failure analysis of CNC system," Journal of Harbin Institute of technology (new series), Vol. 14, No. 2, pp. 197-201, 2007

[31] M. A. Mellal, S. Adjerid, D. Benazzouz, S. Berrazouane and E. J. Williams, "Optimal policy for the replacement of industrial systems subject to technological obsolescence - Using genetic algorithm," Acta Politechnica Hungarica, Vol. 10, No. 1, pp. 197-208, 2013

[32] Y. Wang, Y. Jia and W. Jiang, "Early failure analysis of machining centers: a case study," Reliability engineering and system safety, Vol. 72, No. 1, pp. 91-97, 2001

[33] Y. Wang, R. C. M. Yam, M. J. Zuo and P. Tse, "A comprehensive reliability allocation method for design of $\mathrm{CNC}$ lathes," Reliability engineering and 
system safety, Vol. 72, No. 3, pp. 247-252, 2001

[34] R. B. Patil, B. S. Kothavale, L. Y. Waghmode and S. G. Joshi, "Reliability analysis of CNC turning center based on the assessment of trends in maintenance data: a case study," International journal of quality and reliability management, Vol. 34, No. 9, pp. 1616-1638, 2016

[35] C. R. Kothari, Research methodology - methods and techniques, New Delhi: New age international publishers, 2004

[36] J. I. Ansell and M. J. Phillips, "Strategies for reliability data analysis," in Proc. $11^{\text {th }}$ advances in reliability technology symposium, pp. 272-283, Liverpool, UK, 1990

[37] U. Kumar and B. Klefsjo, "Reliability analysis of hydraulic system of LHD machines using the power law process model," Reliability engineering and system safety, Vol. 35, no. 3, pp. 217-224, 1992

[38] U. Kumar and Y. Haung, "Reliability analysis of a mine production system a case study," in Proceedings annual reliability and maintainability symposium, Atlanta, USA, 1993

[39] U. Kamps, "A concept of generalized order statistics," Journal of statistical planning and inferences, Vol. 48, No. 1, pp. 1-23, 1995

[40] J. F. Lawless and K. Thiagarajah, "A point-process model incorporating renewals and time trends, with application to repairable systems," Technometrices, Vol. 38, No. 2, pp. 131-138, 1996

[41] J. L. Coetzee, "The role of NHPP models in the practical analysis of maintenance data," Reliability engineering and system safety, Vol. 56, No. 2, pp. 161-168, 1997

[42] J. T. Kvaloy and Lindqvist, "TTT-based tests for trend in repairable systems data," Reliability engineering and system safety, Vol. 60, No. 1, pp. 13-28, 1998

[43] E. R. Ziegel, "Statistical methods for the reliability of repairable systems," Technometrices, Vol. 43, No. 3, pp. 371-372, 2001

[44] M. Yanez, F. Joglar and M. Modarres, "Generalized renewal process for analysis of repairable systems with limited failure experience," Reliability engineering and system safety, Vol. 77, No. 2, pp. 167-180, 2002

[45] B. H. Lindqvist, E. Elvebakk and K. Heggland, "The trend-renewal process for statistical analysis of repairable systems," Technometrices, Vol. 45, No. 1, pp. 31-44, 2003

[46] B. Samanta, B. Sarkar and S. K. Mukherjee, "Reliability modeling and performance analyses of an LHD system in mining," The journal of South 
African institute of mining and metallurgy, Vol. 104, No. 1, pp. 1-8, 2004

[47] P. Wang, "Repairable systems reliability trend tests and evaluation," in Proceedings of annual reliability and maintainability symposium, Alexandria, USA, 2005

[48] B. H. Lindqvist, "On the statistical modeling and analysis of repairable systems," Statistical science, Vol. 2, No. 4, pp. 532-551, 2006

[49] P. F. McGoldrick and H. Kulluk, "Machine tool reliability - A critical factor in manufacturing systems," Reliability Engineering, Vol. 14, No. 3, pp. 205221,1986

[50] Y. P. Gupta and T. M. Somers, "Availability of CNC machines: Multipleinput transfer-function modeling," IEEE transactions on reliability, Vol. 38, No. 3, pp. 285-295, 1989

[51] J. Yazhou, S. Guixiang and Zhixin, "A reliability approach to machine tool bearing," Reliability engineering and system safety, Vol. 50, No. 1, pp. 127134,1995

[52] J. Yazhou, W. Molin and J. Zhixin, "Probability distribution of machining center failures," Reliability engineering and system safety, Vol. 50, No. 1, pp. 121-125, 1995

[53] M. Karyagina, W. Wong and L. Vlacic, "Life cycle cost modeling using marked point processes," Reliability engineering and system safety, Vol. 59, No. 3, pp. 291-298, 1998

[54] R. Sehgal, O. P. Gandhi and S. Angra, "Reliability evaluation and selection of rolling element bearings," Reliability engineering and system safety, Vol. 68, No. 1, pp. 39-52, 2000

[55] P. Dasic, "Determination of reliability of ceramic cutting tools on the basis of comparative analysis of different functions distributions," International journal of quality and reliability management, Vol. 18, No. 4, pp. 431-443, 2001

[56] Y. Dai and Y. Jia, "Reliability of a VMC and its improvement," Reliability engineering and system safety, Vol. 74, No. 1, pp. 99-102, 2001

[57] Y. Wang, G. Shen and Y. Jia, "Multidimensional force spectra of CNC machine tools and their applications part two: reliability design of elements," International journal of fatigue, Vol. 25, No. 5, pp. 447-452, 2003

[58] S. S. Jolly and S. S. Wadhwa, "Reliability, availability and maintainability study of high precision special purpose manufacturing machines," Journal of scientific and industrial research, Vol. 63, pp. 512-517, 2004 
[59] B. K. Lad and M. S. Kulkarni, "Integrated reliability and optimal maintenance schedule design: a life cycle cost based approach," International journal of life cycle management, Vol. 3, No. 1, pp. 78-90, 2008

[60] Z. Yang, C. Chen, J. Wang and G. Li, "Reliability assessment of CNC machining center based on Weibull neural network," Mathematical Problems in Engineering, Vol. 2015, pp. 1-8, 2015

[61] F. Chen, X. Chen, Q. Xie, and B. Xu, "Reliability analysis of numerical control lathe based on the field data", International conference on manufacturing science and engineering, pp. 1018-1024, 2015

[62] Z. Yang, J. He, G. Li, H. Tian, X. Du and Y. Kan, "Bayesian method to solve the early failures of numerical control machine tool," Journal of risk and reliability, No. 10, pp. 1-10, 2016

[63] H. Li, Z. Yang, B. Xu, C. Chen, Y. Kan and G. Liu, "Reliability evaluation of NC machine tools considering working conditions," Mathematical Problems in Engineering, Vol. 2016, pp. 1-12, 2016

[64] W. Peng, Y. Li, J. Mi, L. Yu and Z. Huang, "Reliability of complex systems under dynamic conditions: a Bayesian multivariate degradation perspective," Reliability engineering and system safety, Vol. 153, pp. 75-87, 2016

[65] L. Y. Waghmode and R. B. Patil, "Reliability analysis and life cycle cost optimization: a case study from Indian industry," International journal of quality and reliability management, Vol. 33, No. 3, pp. 414-429, 2016

[66] B-J. Sung and J-B. Lee, "Reliability improvement of machine tool changing servo motor", Journal of international council on electrical engineering, Vol. 1, pp. 28-32, 2011 